ARTIGO ORIGINAL

\title{
Parâmetros técnicos, econômicos e ambientais de máquinas florestais em função de configurações do motor e bomba hidráulica
}

\author{
Technical, economic and environmental parameters of forest machines based on \\ motor and hydraulic pump configurations
}

Diego Weslly Ferreira do Nascimento Santos ${ }^{1}$ (1), Domingos Sárvio Magalhães Valente ${ }^{2}$ (1) Haroldo Carlos Fernandes ${ }^{2}$ (D), Amaury Paulo Souza² (1D, Carlos Eduardo Silva Volpato ${ }^{1}$ (1)

${ }^{1}$ Univerisdade Federal de Lavras - UFLA, Lavras, MG, Brasi

Universidade Federal de Viçosa - UFV, Viçosa, MG, Brasil

Como citar: Santos, D. W. F. N., Valente, D. S. M., Fernandes, H. C., Souza, A. P., \& Volpato, C. E. S. (2021).

Parâmetros técnicos, econômicos e ambientais de máquinas florestais em função de configurações do motor e bomba hidráulica. Scientia Forestalis, 49(130), e3520. https://doi.org/10.18671/scifor.v49n130.13

\begin{abstract}
Resumo
Objetivou-se com essa pesquisa quantificar parâmetros técnicos, econômicos e ambientais de máquinas florestais operando em distintas configurações do motor e da bomba hidráulica. O harvester foi configurado para operar com rotação do motor em 2.060; 2.000; 1.950; e 1.900 rpm e vazões da bomba hidráulica em 300; 295; e $290 \mathrm{~L} \mathrm{mim}^{-1}$, totalizando doze combinações. Já o forwarder foi programado para operar com pressão da bomba em 240; 235 e 230 bar e rotação do motor de 1.550; 1.475 e 1.400 rpm, totalizando nove combinações. A análise técnica compreendeu ao estudo de tempos e movimentos, produtividade, consumo horário de combustível e demanda energética. No que se refere a parâmetros econômicos, determinou-se o custo de produção. Já o impacto ambiental foi mensurado por meio da determinação da quantidade de dióxido de carbono emitido. As combinações com rotação do motor em 2.060 rpm e vazão da bomba em $295 \mathrm{~L} \mathrm{~min}^{-1}$ e rotação do motor em $2.000 \mathrm{rpm}$ e vazão da bomba de $300 \mathrm{~L} \mathrm{~min}^{-1}$ asseguraram os melhores resultados técnicos, econômicos e ambientais para o harvester. Com relação ao forwarder os melhores resultados foram obtidos quando a máquina estava programada para operar com pressão da bomba em 240 bar e rotação do motor em 1.475 rpm.
\end{abstract}

Palavras-chave: Colheita florestal; Mecanização florestal; Demanda energética.

\begin{abstract}
The objective of this research was to quantify the technical, economic and environmental parameters of forest machines operating in different motor and hydraulic pump configurations. The harvester has been configured to operate at engine speed at 2.060; 2,000; 1,950; and 1,900 rpm and hydraulic pump flow rates at 300; 295; and $290 \mathrm{~L} \mathrm{~min}^{-1}$, totaling twelve combinations. The forwarder was programmed to operate with pump pressure at 240; 235 and 230 bar and an engine speed of 1,550; 1,475 and 1,400 rpm, totaling nine combinations. The technical analysis comprised the study of times and movements, productivity, hourly fuel consumption and energy demand. Regarding economic parameters, the cost of production was determined. The environmental impact was measured by determining the amount of carbon dioxide emitted. Combinations with engine speed at 2,060 rpm and pump flow at $295 \mathrm{~L} \mathrm{~min}^{-1}$ and engine speed at 2,000 rpm and $300 \mathrm{~L} \mathrm{~min}^{-1}$ pump flow ensured the best technical, economic and environmental results for the harvester. Regarding the forwarder the best results were obtained when the machine was programmed to operate with pump pressure at 240 bar and engine speed at 1,475 rpm.
\end{abstract}

Keywords: Engine speed; Hydraulic pump; Energy demand.

Fonte de financiamento: Coordenação de Aperfeiçoamento de Pessoal de Nível Superior - Brasil (CAPES) - Código de Financiamento 001.

Conflito de interesse: Nada a declarar.

Autor correspondente: diegoweslley89@gmail.com

Recebido: 20 novembro 2019.

Aceito: 14 abril 2020

Editor: Paulo Henrique Müller Silva. (c) (i) Este é um artigo publicado em acesso aberto (Open Access) sob a licença Creative Commons Attribution, que permite uso, distribuição e 


\section{INTRODUÇÃO}

No Brasil, o sistema de colheita de madeira de toras curtas é um dos mais utilizados, sendo caracterizado pela realização de todas as atividades complementares ao corte no próprio local de derrubada da árvore. Nesse sistema, harvester e forwarder são as máquinas mais utilizadas, sendo a primeira para executar o corte e processamento das toras e a segunda empregada na extração. Esses tratores florestais possibilitam que grandes áreas sejam colhidas em pequeno espaço de tempo e assim proporcionam que a crescente demanda de madeira do mercado nacional seja atendida.

Apesar da evolução da colheita de madeira nos últimos anos, é necessária a adoção de medidas mitigadoras com finalidade de reduzir o custo de produção das operações. De acordo com IBÁ (Indústria Brasileira de Árvores, 2015) e Silva et al. (2008) a colheita florestal pode representar até $50 \%$ do custo final da madeira posta na fábrica. Um dos fatores que mais contribui para onerar as operações é a elevada demanda energética das máquinas. Conforme Leite et al. (2014) e Silva et al. (2014) o custo com combustível é o dispêndio que mais onera o custo operacional do harvester, e o segundo que mais contribui com o custo operacional do forwarder (Leite et al., 2014; Silva et al., 2014). Além de elevar o custo, o alto consumo de combustível contribui para o aumento da emissão de gases poluentes, como o dióxido de carbono e metano (Prinz et al., 2018).

$\mathrm{O}$ alto regime de rotação dos motores e vazão da bomba hidráulica, das máquinas florestais, contribuem para a alta demanda energética, por proporcionarem a máxima potência aos componentes que acionam. De acordo com Ramos et al. (2016) o regime de rotação do motor influencia de forma expressiva no consumo horário de combustível de colhedoras canade-açúcar, contudo não afeta a capacidade operacional. Conforme Prinz et al. (2018) ajustes no modo de operação, no que se refere a rotação do motor, afetam de forma diferentes o consumo de combustível dos diversos modelos de harvesters. Segundo Silveira et al. (2013), em algumas circunstâncias, os operadores de máquinas utilizam máximas acelerações e marchas inadequadas o que contribuí para o aumento do consumo de combustível. Já de acordo com Ackerman et al. (2014) o consumo de horário de combustível de máquinas florestais é influenciado pela habilidade e nível de treinamento do operador.

Mediante ao exposto, objetivou-se com a presente pesquisa avaliar o efeito de alterações nas configurações do motor e bomba de hidráulica de harvester e forwarder sobre parâmetros técnicos, econômicos e ambientais.

\section{MATERIAL E MÉTODOS}

\section{Caracterização da área de estudo}

A pesquisa foi executada em áreas de operações de colheita florestal localizadas no município de Nova Viçosa - BA. A região apresenta temperatura média anual de $24,4{ }^{\circ} \mathrm{C}$ e precipitação pluviométrica média anual de $1.350 \mathrm{~mm}$. As áreas onde foram alocadas as parcelas experimentais apresentavam relevo plano, povoadas com clones híbridos de Eucalyptus grandis $x$ Eucalyptus urophylla, plantados em espaçamento de 4 metros entre linhas e 2,5 metros entre plantas. A coleta de dados foi realizada no período diurno, sendo iniciadas as $06 \mathrm{~h} 00 \mathrm{~min}$ e finalizadas as $15 \mathrm{~h} 00 \mathrm{~min}$. Os testes foram conduzidos na ausência de chuva.

\section{Sistema de colheita}

A pesquisa foi executada em um sistema de colheita florestal de toras curtas (cut to length) composto pelas máquinas harvester e forwarder.

O harvester era responsável pelo corte e processamento das árvores, deixando feixes sobre a superfície do solo com toretes de 6,20 metros de comprimento. A máquina realizava simultaneamente a derrubada de quatro linhas de árvores. A extração da madeira do interior dos talhões até as margens das estradas era realizada pelo forwarder. A máquina adentrava no talhão de marcha ré e realizava o carregamento dos feixes presentes em ambos os lados do ramal. 


\section{Unidades experimentais}

A pesquisa foi executada em nos Volumes Médios Individuas (VMI) das árvores de $0,10 \mathrm{~m}^{3} \mathrm{arv}^{-1}$ para o harvester e de 0,14 $\mathrm{m}^{3}$ árvore ${ }^{-1}$ para o forwarder. Em cada volume, as operações com harvester foram executadas em quatro rotações do motor, 2.060, 2.000; 1.950; e 1.900 rpm, e três vazões da bomba hidráulica, 300; 295; e $290 \mathrm{~L} \mathrm{~min}^{-1}$, totalizando doze tratamentos. Com relação ao forwarder, a pesquisa foi executada em três pressões da bomba hidráulica, 240; 235; e 230 bar e três rotações do motor, totalizando 9 tratamentos. Para cada tratamento foram demarcadas 10 parcelas experimentais, com área de $380 \mathrm{~m}^{3}$ e 60 árvores.

As configurações do motor e bomba hidráulica utilizadas na pesquisa foram definidas em um estudo preliminar, onde foi observado que não era possível operar o harvester com valores de rotação do motor e vazão da bomba inferior a $1.900 \mathrm{rpm}$ e $290 \mathrm{~L} \mathrm{~min} \mathrm{~m}^{-1}$, respectivamente. Com relação ao forwarder, não era viável operar a máquina com valores inferiores de rotação do motor e pressão da bomba hidráulica de 1.400 rpm e 230 bar.

\section{Máquinas utilizadas}

O harvester utilizado foi uma combinação entre a escavadeira hidráulica da marca Komatsu, modelo PC200F-8M0 e o cabeçote também da marca Komatsu, modelo $370 \mathrm{E}$. A PC200F-8M0 era uma máquina de esteiras, equipada com o motor diesel Komatsu SAA6D107E-1 de 6 cilindros e $110 \mathrm{~kW}$ de potência nominal a $2.000 \mathrm{rpm}$. O sistema hidráulico da máquina era do tipo Hydraumind, composto por duas bombas hidráulicas da marca Komatsu, modelo HPV95+95, ambas de pistão com deslocamento variável e vazão máxima, para cada bomba, de 219 litros por minuto.

O forwarder utilizado, foi o da marca Komatsu, modelo 895 com tração nas oitos rodas. A máquina é equipada com o motor AGCO power 74CW3 de 6 cilindros e 193 kW de potência a 1.950 rpm. A caixa de carga tinha capacidade para 23 metros cúbicos de madeira. O sistema hidráulico do forwarder era composto por uma bomba hidráulica de pistão variável com vazão máxima de 360 litros por minuto a 2.000 rpm e pressão máxima de trabalho de 24,5 MPa.

\section{Instrumentação da máquina}

A quantidade de combustível consumido, em ambas as máquinas, foi determinada por meio da instalação de um medidor de fluxo volumétrico (fluxômetro) no sistema de alimentação de combustível do motor, logo após o filtro primário. O medidor de fluxo utilizado foi o da marca FLUWMATE M-III ${ }^{\circledR}$, modelo LSF41C. Juntamente ao fluxômetro foi instalado um visor gráfico (indicador) da marca TechMeter, modelo LCT. O visor gráfico foi programado previamente para exibir os valores de consumo horário de combustível instantâneo e o consumo em determinado período, ambos em litros por hora.

\section{Determinação da rotação do motor}

Para harvester e forwarder a rotação do motor eram controlados pelo Sistema de Controle e Informação da máquina MaxiXplorer. Os valores de rotação do motor selecionados eram exibidos instantaneamente nos monitores dos tratores florestais. O harvester realizou o corte da madeira com rotações do motor em 2.060; 2.000; 1.950 e 1.900 rpm. Já o forwarder foi programado para trabalhar nas rotações do motor de 1.550; 1.475 e 1.400 rpm.

\section{Determinação da vazão e pressão da bomba hidráulica}

O harvester trabalhou com vazões da bomba hidráulica de 300; 295 e 290 litros por minuto, sendo as alterações realizadas diretamente no Sistema de Controle e Informação Maxixplorer e mostradas no monitor do trator florestal. A vazão da bomba hidráulica foi confirmada com base na rotação dos rolos alimentadores do cabeçote, conforme a Equação 1. A rotação dos rolos do cabeçote foi determinada mediante a utilização de um fototacômetro digital da marca Mimipa, modelo MDT-2244B. 
$\mathrm{VB}=\frac{\mathrm{De} 2}{1000} \mathrm{Rm}$

em que: VB = vazão da bomba hidráulica $\left(\mathrm{L} \mathrm{min}^{-1}\right)$; De = Volume deslocado pelo motor do rolo $\left(\mathrm{cm}^{3}\right) ; \mathrm{Rm}=$ rotação dos rolos alimentadores (rpm).

A bomba hidráulica do forwarder foi ajustada para trabalhar com as pressões de 240; 235 e 230 bar. Os valores selecionados eram ajustados por meio da regulagem manual na bomba hidráulica, fazendo o uso de ferramentas. Os valores de pressão do circuito hidráulico eram exibidos instantaneamente no monitor da máquina por meio do sistema operacional MaxiXplorer.

\section{Parâmetros técnicos}

O estudo de tempos e movimentos foi realizado por do meio do método de tempo contínuo, sendo instalado nas máquinas um sistema de vídeo composto por quatro câmeras de vídeo, um monitor de sete polegadas e um Gravador de Vídeo Digital Móvel (MVDR). Posteriormente os vídeos foram analisados e mensurados o tempo despedido com cada operação executada pelas máquinas. Foi executado um estudo preliminar com o objetivo de determinar o número mínimo de observações necessárias para proporcionar um erro de amostragem admissível máximo de 5\%, sendo utilizada a Equação 2, conforme metodologia proposta por Barnes (1968).

$\mathrm{N}^{\prime}=\left[\frac{40 \mathrm{~N}}{\sum \mathrm{X}} \sqrt{\frac{\sum \mathrm{X}^{2}-\left(\sum \mathrm{X}\right)^{2} / \mathrm{N}}{\mathrm{N}-1}}\right]^{2}$

em que: $N^{\prime}$ = número de observações necessárias; $N$ = número de observações utilizadas no estudo preliminar; e $\mathrm{X}=$ valor de cada observação.

O ciclo operacional do harvester foi subdividido nas operações de deslocamento e busca, corte de derrubada e processamento.

O deslocamento e busca iniciava quando a máquina finaliza o processamento da madeira do ciclo anterior ou quando a máquina iniciava o deslocamento dentro do talhão em busca da árvore a ser abatida. A operação era finalizada quando o cabeçote era posicionado na árvore. O corte de derrubada iniciava quando o cabeçote era posicionado na árvore, estando às facas superior e inferior e os rolos alimentadores fixados na árvore. A operação era finalizada quando a árvore era posicionada no sentido horizontal, sendo iniciada a movimentação da mesma. O processamento compreendia as operações de descascamento, desgalhamento, traçamento e empilhamento. Iniciava quando a tora de madeira começa a ser movimentada, pelos rolos alimentadores, no sentido horizontal e era finalizado quando o último torete era seccionado.

O ciclo operacional do forwarder foi subdividido nas operações de deslocamento vazio, carregamento, deslocamento carregado e descarregamento.

Deslocamento vazio compreendia a movimentação da máquina dentro do talhão com a caixa de carga vazia. A operação iniciava quando a máquina começava a ser deslocada da margem da estrada em direção ao interior do talhão e era finalizada quando a máquina era estacionada ao lado do primeiro feixe de madeira a ser carregado. O carregamento começava no momento em que o operador retirava a grua de dentro da caixa de carga vazia e deslocava a mesma em direção ao primeiro feixe de madeira a ser carregado. Essa operação era finalizada quando a caixa de carga estava totalmente completa e a grua posicionada sobre a madeira. Deslocamento carregado iniciava com o deslocamento da máquina do interior do talhão, com a caixa de carga completa, em direção a margem da estrada, sendo finalizado quando o operador posicionava e parava a máquina ao lado da pilha de madeira. O descarregamento iniciava quando o operador movimentava a grua que estava sobre a madeira e era finalizado quando o último feixe de madeira era descarregado, estando a grua dentro da caixa de carga vazia. 
A produtividade das máquinas, consumo horário de combustível e demanda energética foram calculados de acordo com as Equações 3; 4; e 5, respectivamente.

$\operatorname{Pr}=\frac{\mathrm{V}}{\mathrm{T}}$

em que: $\operatorname{Pr}=$ produtividade $\left(\mathrm{m}^{3} \mathrm{~h}^{-1}\right) ; \mathrm{V}=$ Volume de madeira na parcela $\left(\mathrm{m}^{3}\right) ; \mathrm{T}=$ tempo gasto na parcela (h).

$\mathrm{Ch}=\frac{\mathrm{Q}}{\mathrm{T}} 3,6$

em que: $C h=$ consumo horário de combustível $\left(L h^{-1}\right) ; \mathrm{Q}=$ Quantidade de combustível consumido na parcela $(\mathrm{mL}) ; \mathrm{T}$ = tempo gasto na parcela $(\mathrm{s})$.

$\mathrm{De}=\frac{\mathrm{Pr}}{\mathrm{Q}}$

em que: De = demanda energética $\left(L \mathrm{~m}^{-3}\right) ; \operatorname{Pr}=$ produtividade $\left(\mathrm{m}^{3} \mathrm{~h}^{-1}\right) ; \mathrm{Ch}=$ consumo horário de combustível $\left(L h^{-1}\right)$.

\section{Parâmetros econômicos}

O custo de produção, em US $\$ \mathrm{~m}^{-3}$, foi determinado por meio do quociente entre o custo operacional e a produtividade da máquina.

O custo operacional foi determinado mediante o somatório dos custos fixos e variáveis. Algumas variáveis necessárias para o cálculo foram fornecidas pela empresa e outras obtidas por meio de avaliações em campo. O consumo horário de combustível foi à única variável alterada nos treze tratamentos estudados, sendo as demais mantidas fixas. Tal medida tinha objetivo de verificar o efeito isolado do consumo horário de combustível sobre o custo operacional. Utilizou-se uma taxa de câmbio de 1 US\$ = R \$3,915, cotado no dia 27/03/2019.

Com relação aos custos fixos, calculou-se o custo com depreciação, juros, seguro, segurança, pessoal administrativo, salário do operador e custo com pessoal de manutenção. Já para custo variável, determinou-se o custo com combustível, óleo hidráulico, óleo lubrificante, graxa, óleo de corrente, peças de reposição e organização da área do módulo.

\section{Parâmetros ambientais}

A quantidade de dióxido de carbono equivalente $\left(\mathrm{CO}_{2 \text { eq }}\right)$ emitido pelo harvester e forwarder durante a colheita de madeira, foi determinado de acordo com a Equação 6 . Foi estabelecido um fator de emissão específico para dióxido de carbono, conforme determinado pela Intergovernmental Panel on Climate Change (2006).

$\mathrm{QE}=\frac{\mathrm{FACh} P c \mathrm{c}}{\mathrm{P}}$

em que: $\mathrm{QE}=$ quantidade de dióxido de carbono $\left(\mathrm{kg} \mathrm{m}^{-3}\right) ; \mathrm{FA}=$ fator de emissão $\left(\mathrm{Kg} \mathrm{TJ}^{-1}\right)$; $\mathrm{Ch}=$ Consumo horário de combustível $\left(\mathrm{Kg} \mathrm{h}^{-1}\right) ; \mathrm{Pcc}=$ Poder calorífico $\left(\mathrm{TJ} \mathrm{kg}^{-1}\right)$; e $\mathrm{P}=$ produtividade $\left(\mathrm{m}^{3} \mathrm{~h}^{-1}\right)$. 


\section{Análise dos dados}

O experimento do harvester foi realizado em um esquema fatorial $4 \times 3$, sendo quatro rotações do motor e três vazões da bomba hidráulica, totalizando 12 tratamentos. 0 experimento de forwarder conduzido em um esquema fatorial 3×3, sendo 3 pressões da bomba hidráulica e três rotações do motor, totalizando nove (9) tratamentos. Para ambos os experimentos, foi considerado um delineamento inteiramente casualizado (DIC), com 13 repetições por tratamento.

Os dados referentes ao estudo de tempos e movimentos, rendimento operacional, consumo horário de combustível, demanda energética, custo de produção e emissão de dióxido de carbono foram analisados, dentro de cada volume, por meio de superfície de resposta. Os modelos foram selecionados baseados na significância dos coeficientes de regressão, utilizando o teste " $t$ " e adotando o nível de $5 \%$ de probabilidade, no coeficiente de determinação e no comportamento do fenômeno em estudo.

\section{RESULTADOS E DISCUSSÃO}

\section{Parâmetros técnicos}

A rotação do motor e vazão da bomba hidráulica apresentaram efeito significativo e quadrático sobre o tempo de todas as operações que compõem o ciclo operacional do harvester (Tabela 1). Os menores valores de tempo da operação deslocamento e busca, 5,20; e 5,33 segundos por ciclo, foram observados quando a máquina trabalha com rotação do motor em $2.060 \mathrm{rpm}$ e com vazão da bomba hidráulica em 300 ou $295 \mathrm{~L} \mathrm{~min}^{-1}$, respectivamente. Nas combinações de rotação do motor em 2.060 rpm e vazão da bomba em 300 ou $295 \mathrm{~L} \mathrm{~min}^{-1} \mathrm{e}$ rotação do motor em 2.000 rpm e vazão da bomba em 300 ou $295 \mathrm{~L} \mathrm{~min}^{-1}$ foram obtidos os menores valores de tempo, 4,03; 4,11; 4,11; e 4,17 segundos por ciclo, da operação corte de derrubada, respectivamente. Com relação à operação processamento, o melhor desempenho da máquina, 14,27; e 14,34 segundos por ciclo, foi observado na rotação do motor em 2.060 rpm e vazão da bomba em $300 \mathrm{~L} \mathrm{~min}^{-1}$ e rotação do motor em 2.000 rpm e vazão da bomba em 300 $L$ min $^{-1}$, respectivamente.

Tabela 1: Equações ajustadas do tempo por ciclo $(s$ ciclo-1) das operações que compõem o ciclo operacional do harvester.

\begin{tabular}{ccc}
\hline Operação & Modelo & $\mathbf{R}^{\mathbf{2}} \mathbf{( \% )}$ \\
\hline Deslocamento e busca & $\mathrm{Tc}=11,65+2,13110^{-5} * \mathrm{RM}^{2}+1,0064610^{-3} * \mathrm{VB}^{2}-3,033310^{-4} * \mathrm{RM} \mathrm{VB}$ & 84 \\
Corte de derrubada & $\mathrm{TC}=7,36+7,56510^{-6} \mathrm{RM}^{2}+3,4110^{-4} * \mathrm{VB}^{2}-1,0710^{-4} * \mathrm{RM} \mathrm{VB}$ & 91 \\
Processamento & $\mathrm{Tc}=20+1,5410^{-5} * \mathrm{RM}^{2}+6,6810^{-4} * \mathrm{VB}^{2}-2,12310^{-4} * \mathrm{RM} \mathrm{VB}$ & 88 \\
\hline
\end{tabular}

A redução da rotação do motor do motor e vazão da bomba hidráulica reduziram a potência dos motores hidráulicos que promoviam o deslocamento da máquina, o acionamento de atuadores hidráulicos, da serra do sabre e dos rolos alimentadores do cabeçote. Por essa razão ocorreu o aumento do tempo de reação dos mecanismos acionados hidraulicamente e também o aumento do tempo para os mecanismos atingirem as velocidades padrão de trabalho. Além disso, os movimentos da grua e giro da máquina base ficaram mais lentos. Por esses motivos, o tempo das operações deslocamento e busca, corte de derrubada e processamento aumentaram, principalmente quando a máquina estava operando com rotação do motor abaixo de $1.950 \mathrm{rpm}$ e vazão da bomba abaixo de $295 \mathrm{~L} \mathrm{~min}^{-1}$.

Na Tabela 2 constam os modelos ajustados, e os respectivos coeficientes de determinação, do tempo por ciclo de todas as operações do ciclo operacional do forwarder. A pressão da bomba e rotação do motor não apresentaram efeito significativo sobre o tempo da operação deslocamento vazio, sendo o tempo médio de 1,07 minutos ciclo-1. O tempo da operação carregamento sofreu efeito significativo e quadrático da rotação do motor e efeito significativo e linear da pressão da bomba. Os menores valores de tempo da operação, 7,66; 7,71; 7,67; e 
7,74 minutos por ciclos, foram observados nas combinações de rotação do motor e pressão da bomba de 1.550 rpm com 240 bar, 1550 rpm com 235 bar, 1475 rpm com 240 bar e 1475 rpm com 230 bar, respectivamente. Os valores de tempo da operação deslocamento carregado não sofreram impacto significativo da pressão da bomba, contudo houve efeito significativo e quadrático da rotação do motor. O menor tempo, 0,50 minutos por ciclo, foi verificado nas rotações do motor de 1.550 e $1.475 \mathrm{rpm}$. Os tempos da operação descarregamento sofreu efeito significativo e quadrático de ambas as variáveis independentes. Os valores inferiores, 5,74; 5,78; 5,76; e 5,78 minutos por ciclo, foram alcançados nas combinações de pressão da bomba e rotações do motor de 240 bar com 1.550 rpm, 240 bar com 1.475 rpm, 235 bar com 1.550 rpm e 230 bar com 1.550 rpm, respectivamente.

Tabela 2: Equações ajustadas do tempo por ciclo (min ciclo-1) das operações que compõem o ciclo operacional do forwarder.

\begin{tabular}{|c|c|c|}
\hline Operação & Modelo & $R^{2}(\%)$ \\
\hline Deslocamento vazio & $T C=-12,14+5,84310^{-2 n s} P B+9,5510^{-3 n s} \mathrm{RM}-4,21510^{-5 n s} \mathrm{~PB} R M$ & 59 \\
\hline Carregamento & $\mathrm{Tc}=204-2,403710^{-1} * \star \mathrm{RM}+7,35510^{-5} * * \mathrm{RM}^{2}-1,13410^{-1} * \mathrm{~PB}+7,1910^{-5} * \mathrm{~PB} \mathrm{RM}$ & 99 \\
\hline $\begin{array}{l}\text { Deslocamento } \\
\text { carregado }\end{array}$ & $\mathrm{Tc}=2,31+1710^{-2 n s} \mathrm{~PB}-4,7610^{-3 *} \mathrm{RM}+2,510^{-6 * *} \mathrm{RM}^{2}-1,2210^{-5 *} \mathrm{~PB} \mathrm{RM}$ & 98 \\
\hline Descarregamento & $\mathrm{TC}=6,56-7,4110^{-6} * \mathrm{~PB}^{2}-1,6310^{-7} * * \mathrm{RM}^{2}$ & 82 \\
\hline
\end{tabular}

A influência da pressão da bomba e rotação do motor sobre o tempo das operações do forwarder ocorreu devido à redução da velocidade de deslocamento da máquina e também redução da velocidade de giro da grua hidráulica. O carregamento foi à operação mais afetada pela alteração das variáveis, ao comparar o tempo da operação na rotação do motor em $1.550 \mathrm{rpm}$ com o valor na rotação do motor em $1.400 \mathrm{rpm}$, tem-se o aumento de 0,93 minutos por ciclo. Durante o carregamento dos feixes de madeira, o operador mantinha a máquina em deslocamento, por essa razão, essa referida operação era a que demandava maior potência da máquina para ser executada.

A rotação do motor e vazão da bomba hidráulica apresentaram efeito significativo e quadrático sobre a produtividade do harvester (Figura 1A). A maior produtividade, 16,24 $\mathrm{m}^{3} \mathrm{~h}^{-1}$, foi obtida na rotação do motor de $2.060 \mathrm{rpm}$ e vazão da bomba hidráulica de $300 \mathrm{~L} \mathrm{~min}^{-1}$. Valor similar, 15,96 $\mathrm{m}^{3} \mathrm{~h}^{-1}$, foi verificado nas combinações de rotação do motor e vazão da bomba de 2060 rpm com $295 \mathrm{~L} \mathrm{~min}^{-1}$, e $2.000 \mathrm{rpm}$ com $300 \mathrm{~L} \mathrm{~min}^{-1}$. A pressão da bomba não afetou de forma significativa a produtividade do forwarder, no entanto a rotação do motor apresentou efeito significativo e quadrático (Figura 1B). Na pressão da bomba de 240 bar e rotações do motor em 1.550 e $1.475 \mathrm{rpm}$ a produtividade do forwarder foi de 69,64 e 69,30 $\mathrm{m}^{3} \mathrm{~h}^{-1}$, respectivamente, valores estes considerados semelhantes.

A partir dos resultados de rendimento operacional percebe-se que é inviável operar harvester e forwarder com baixos valores de rotação do motor e vazão ou pressão da bomba hidráulica. Ao comprar a produtividade do harvester na rotação do motor de $2.060 \mathrm{rpm}$ e vazão da bomba em $300 \mathrm{~L} \mathrm{~min}^{-1} \mathrm{com}$ os valores na rotação do motor em $1.900 \mathrm{rpm}$ e vazão da bomba de $290 \mathrm{~L} \mathrm{~min}^{-1}$, tem-se uma redução de $1,23 \mathrm{~m}^{3} \mathrm{~h}^{-1}$ na produtividade. A produtividade do forwarder com pressão da bomba em 240 bar e rotação do motor em $1.550 \mathrm{rpm}$ aumenta $6,68 \mathrm{~m}^{3} \mathrm{~h}^{-1} \mathrm{em}$ relação aos valores obtidos na pressão da bomba de 240 bar e rotação do motor em $1.400 \mathrm{rpm}$. Tal situação ocorreu porque em baixas rotações do motor e pressão ou vazão da bomba hidráulica a máquina não tem sua máxima potência e consequentemente reduz o torque disponível, tornando todos os movimentos da máquina mais lentos. Contudo é possível operar as máquinas com valores intermediários de rotação do motor e pressão ou vazão da bomba hidráulica, sem que ocorram decréscimos relevantes no rendimento operacional. 
A $P=4,98-2,30410^{-5 *} R^{2}-1,03810^{-3 *} \mathrm{VB}^{2}+3,27610^{-4} * \mathrm{RM} V B$

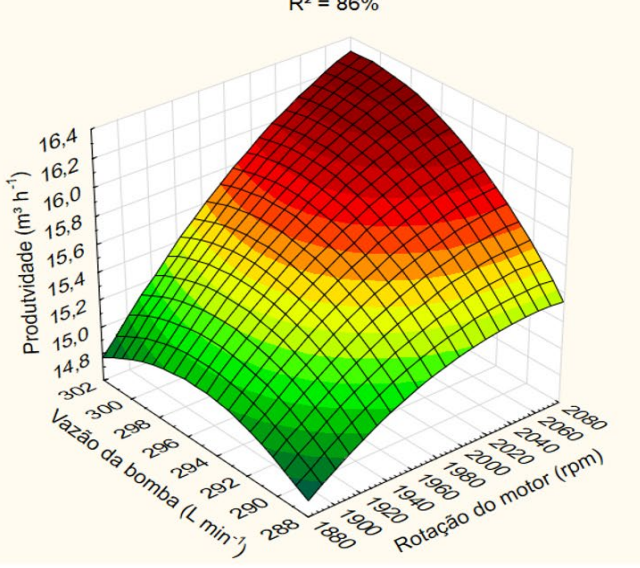

B

$\operatorname{Pr}=-1161+1,8810^{-2}{ }^{n s} P B+1,61756^{\star *} R M-5,332310^{-4 * \star} R M^{2}$ $R^{2}=99 \%$

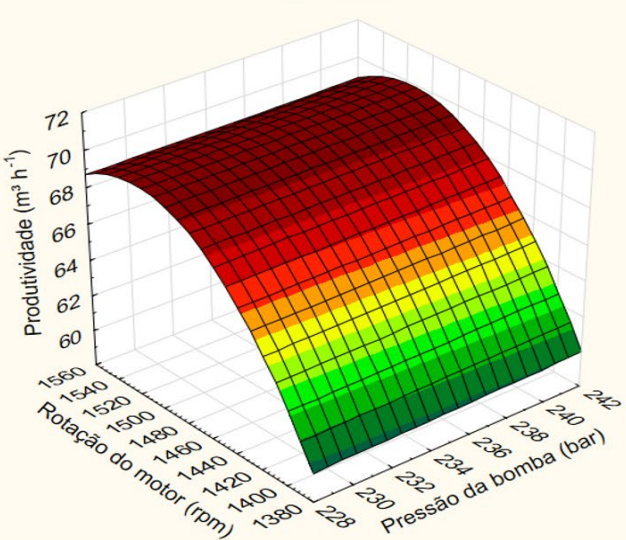

Figura 1. Comportamento e equação ajustada da produtividade $(P)$ do harvester (1A) e forwarder (1B). Onde: $\mathrm{RM}=$ rotação do motor (rpm); VB = vazão da bomba hidráulica (bar); PB = pressão da bomba hidráulica; * = significativo ao nível de $5 \%$ de probabilidade; ** = significativo ao nível de $1 \%$ de probabilidade; $^{\text {ns }}=$ não significativo; e $\mathrm{R}^{2}$ = coeficiente de determinação.

Resultados distintos aos desta pesquisa, foram encontrados por Santos et al. (2018), pois os autores afirmaram que o regime de rotação do motor não influencia de forma significativa na produtividade de harvester em um povoamento florestal com volume médio de $0,25 \mathrm{~m}^{3}$ árvore ${ }^{-1}$. Já de acordo com Ramos et al. (2016) a influência do regime de rotação do motor sobre a capacidade operacional de colhedoras de cana-de-açúcar depende da velocidade de deslocamento da máquina, sendo que em baixas velocidades, até $4 \mathrm{~km} \mathrm{~h}^{-1}$, não existe efeito significativo.

A rotação do motor e a vazão da bomba hidráulica apresentaram efeito significativo e linear sobre o consumo horário de combustível do harvester (Figura 2A). A maior quantidade de diesel consumida, $23,00 \mathrm{~L} \mathrm{~h}^{-1}$, foi observada na rotação do motor de 2.060 rom e vazão da bomba de $300 \mathrm{~L} \mathrm{~min}^{-1}$, cerca de 3,29 L h-1 a mais quando comparado com o valor obtido na rotação do motor de $1.900 \mathrm{rpm}$ e vazão da bomba de $290 \mathrm{~L} \mathrm{~min}^{-1}$. O consumo horário de combustível do forwarder não foi influenciado de forma significativa pela pressão da bomba, no entanto a rotação do motor apresentou influência significativa e linear (Figura 2B). O consumo horário médio da máquina nas rotações do motor de 1.550; 1.475; e 1.400 rpm foi de 16,$67 ; 16,08$; e $15,48 \mathrm{~L} \mathrm{~h}^{-1}$, respectivamente. $\mathrm{Ch}=-43,4275+1,410^{-2 * *} \mathrm{RM}+1,25310^{-1 * *} \mathrm{VB}$

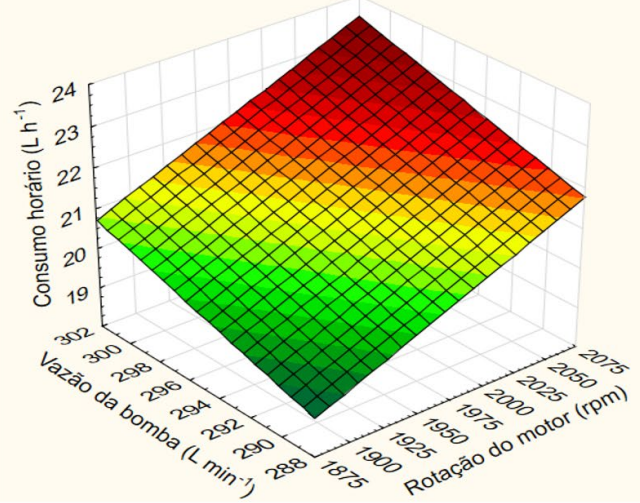

B

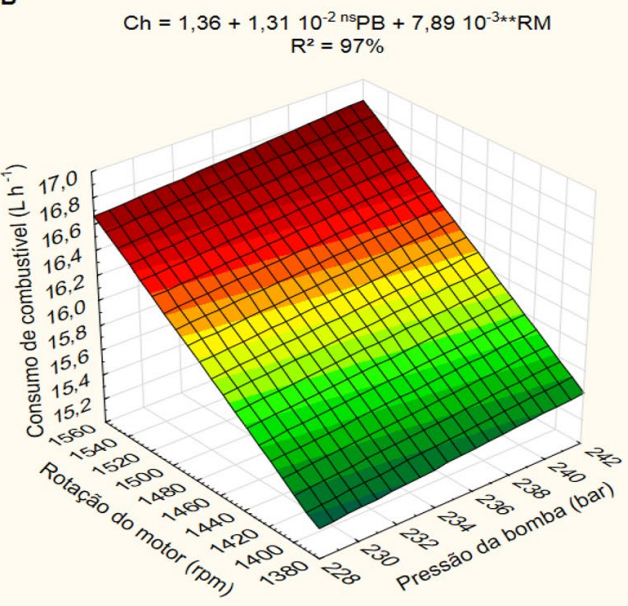

Figura 2. Comportamento e equação ajustada do consumo horário de combustível (Ch) do harvester (2A) e forwarder (2B). Onde: RM = rotação do motor (rpm); VB = vazão da bomba hidráulica (bar); $\mathrm{PB}=$ pressão da bomba hidráulica; $* *$ = significativo ao nível de $1 \%$ de probabilidade; ns = não significativo; e $\mathrm{R}^{2}$ = coeficiente de determinação. 
O efeito da rotação do motor sobre o consumo horário de combustível das máquinas ocorreu devido ao maior número de combustões nas maiores rotações do motor. Resultados semelhantes foram obtidos por Santos et al. (2018) e Ramos et al. (2016). Conforme Spinelli et al. (2018) ajustes no regime de rotação dos motores de picadores de madeira podem reduzir em $17 \%$ o consumo horário de combustível. Tais resultados demonstram que as máquinas são operadas em acelerações máximas o que proporciona elevada potência e consequentemente o alto consumo horário de combustível, independentemente das condições de trabalho. Dessa forma torna-se necessário o treinamento de operadores de máquinas, objetivando a adequação do regime de rotação do motor com a real demanda de potência. Contudo, cabe destacar, que baixo o consumo horário de combustível pode proporcionar uma falsa impressão de vantagem, visto que seu cálculo não leva em consideração a quantidade produzida.

A demanda energética do harvester sofreu influência significativa e quadrática da rotação do motor e vazão da bomba hidráulica (Figura 3A). O menor valor, $1,31 \mathrm{~L} \mathrm{~m}^{-3}$, foi obtido na rotação do motor de $1.900 \mathrm{rpm}$ e vazão da bomba de $290 \mathrm{~L} \mathrm{~min}^{-1}$. A pressão da bomba não afetou de forma significativa a demanda energética do forwarder, caso contrário ocorreu com a rotação do motor que influenciou de maneira significativa e quadrática, sendo o menor valor, $0,235 \mathrm{~L} \mathrm{~m}^{-3}$, obtido na rotação do motor de $1.475 \mathrm{rpm}$ (Figura 3B).
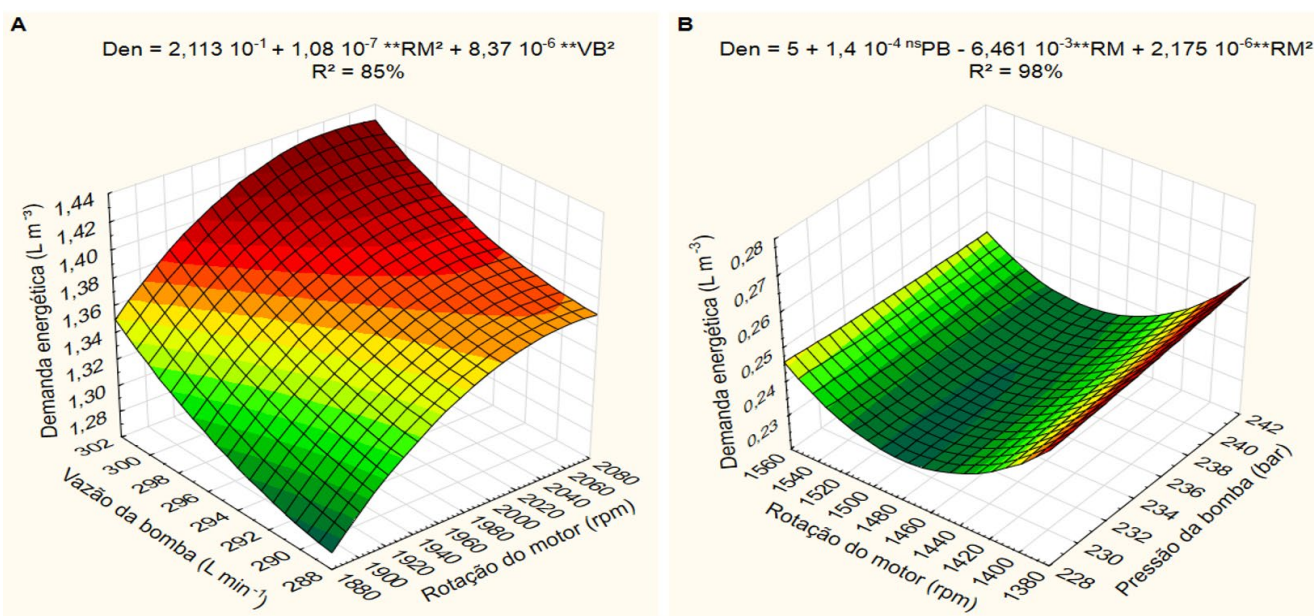

Figura 3. Comportamento e equação ajustada da demanda energética (Den) do harvester (3A) e forwarder (3B). Onde: RM = rotação do motor (rpm); VB = vazão da bomba hidráulica (bar); $\mathrm{PB}=$ pressão da bomba hidráulica; ** = significativo ao nível de $1 \%$ de probabilidade; ns = não significativo; e $\mathrm{R}^{2}$ = coeficiente de determinação.

O menor valor de demanda energética de harvester na combinação com rotação do motor de 1.900 rpm e vazão da bomba de $290 \mathrm{~L} \mathrm{~min}^{-1}$, se deve a elevada redução do consumo horário de combustível e decréscimo pouco expressivo da produtividade. Contudo, é mais viável tecnicamente, operar a máquina com rotação do motor em 2.000 rpm e vazão da bomba hidráulica em $300 \mathrm{~L} \mathrm{~min}^{-1}$, pois tal combinação apresenta baixa demanda energética e não promoveu perdas significativa de produtividade. Com relação ao forwarder, a rotação do motor em $1.400 \mathrm{rpm}$ afetou de forma expressiva a produtividade, por essa razão a menor demanda energética foi obtida na rotação do motor de $1.475 \mathrm{rpm}$, a qual reduziu o consumo horário de combustível e não provocou perdas de produtividade. Na pesquisa desenvolvida por Prinz et al. (2018) os menores valores de demanda energética do harvester Scorpion king foram obtidos quando a máquina estava configurada para operar no modo ECO, o qual desfrutava do regime intermediário de rotação do motor. Contudo, os autores ressaltam que baixos valores de rotação do motor comprometem o rendimento operacional da máquina, resultados estes que corroboram com os encontrados na atual pesquisa.

De acordo com Spinelli et al. (2018) ajustes na rotação do motor de picadores florestais promovem a redução do consumo horário de combustível e não provocam perdas na produtividade 
e qualidade da madeira. Na pesquisa desenvolvida por Ramos et al. (2016) os menores valores de demanda energética de uma colhedora de cana-de-açúcar foram obtidos no menor regime de rotação do motor. A partir dos resultados apresentados e os da atual pesquisa, verifica-se que a influência do regime de rotação do motor, sobre a demanda energética das máquinas, ocorre de formas distintas. Dessa forma o ajuste da rotação deve levar em consideração os diferentes modelos e tipos de máquinas, assim como as condições operacionais, para não haver perdas de rendimento.

\section{Parâmetros econômicos}

A rotação do motor e vazão da bomba hidráulica apresentaram efeito significativo e quadrático sobre o custo de produção do harvester, sendo o menor valor, US\$4,81 $\mathrm{m}^{-3}$, obtido na combinação com rotação do motor de $2.060 \mathrm{rpm}$ e vazão da bomba de $300 \mathrm{~L} \mathrm{~min}^{-1}$ (Figura 4A). O custo de produção do forwarder não sofreu efeito significativo da pressão da bomba hidráulica, porém houve efeito significativo e quadrático da rotação do motor sobre a variável (Figura 4B). O menor valor, US\$ 0,97m³ , foi obtido na rotação do motor de $1.475 \mathrm{rpm}$.
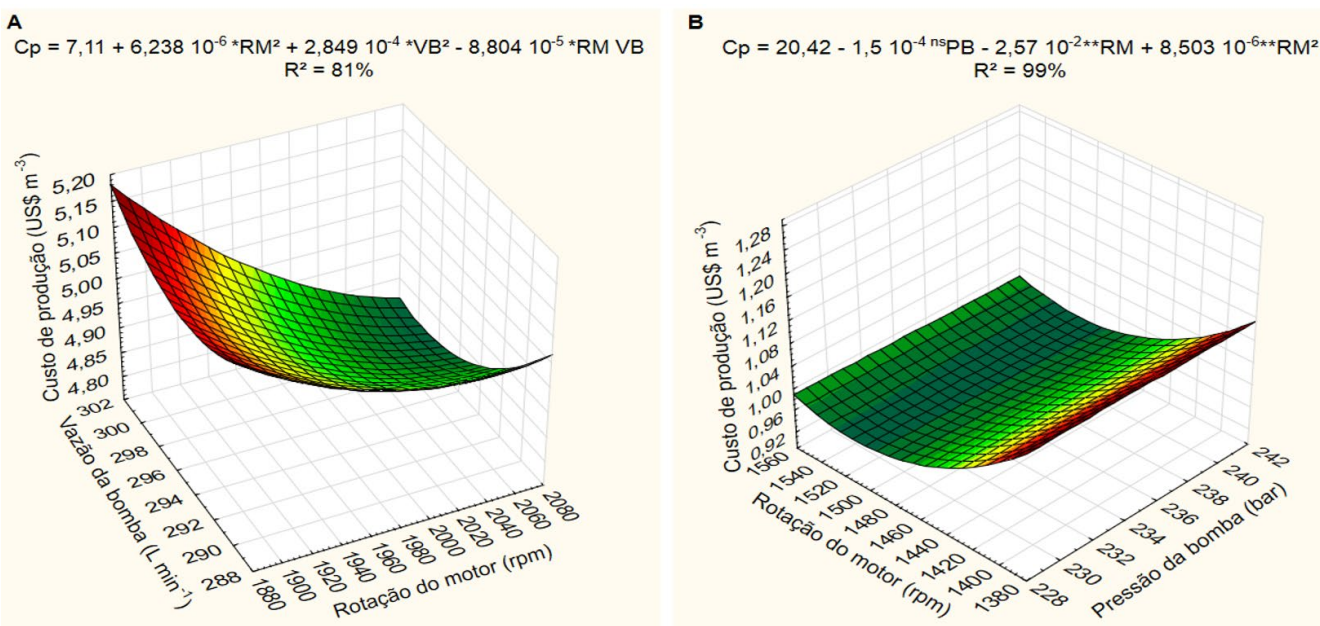

Figura 4. Comportamento e equação ajustada do custo de produção (Cp) do harvester (4A) e forwarder (4B). Onde: RM = rotação do motor (rpm); VB = vazão da bomba hidráulica (bar);

$\mathrm{PB}=$ pressão da bomba hidráulica; ** = significativo ao nível de $1 \%$ de probabilidade; * = significativo ao nível de $5 \%$ de probabilidade; ${ }^{\text {ns }}=$ não significativo; e $\mathrm{R}^{2}=$ coeficiente de determinação.

Apesar do elevado custo operacional do harvester na rotação do motor de 2.060 rpm e vazão da bomba de $300 \mathrm{~L} \mathrm{~min}^{-1}$, a referida combinação apresentou o menor custo de produção, devido à alta produtividade. Cabe ressaltar, que devido à forma como o custo de produção é calculado, a produtividade apresenta efeito mais expressivo, quando comparado com o custo operacional. Dessa forma, pequenos decréscimos no rendimento operacional, aumentam de forma expressiva o custo final da madeira. O menor custo de produção do forwarder na rotação do motor de 1475 rpm, ocorreu devido a redução do custo operacional e manutenção da produtividade da máquina. O custo com combustível foi o dispêndio responsável por promover a redução do custo operacional, sendo o mesmo cerca de $1 \%$ a menos na rotação do motor de 1.475 rpm em relação à rotação do motor de $1.550 \mathrm{rpm}$.

\section{Parâmetros ambientais}

A rotação do motor e vazão da bomba hidráulica apresentaram efeito significativo e quadrático sobre a quantidade de dióxido de carbono $\left(\mathrm{CO}_{2 \text { eq }}\right)$ emitido pelo harvester (Figura $\left.5 \mathrm{~A}\right)$. O harvester emitiu uma menor quantidade de gás, $3,63 \mathrm{~kg} \mathrm{~m}^{-3}$, quando estava operando com rotação do motor em $1.900 \mathrm{rpm}$ e vazão da bomba de $290 \mathrm{~L} \mathrm{~min}^{-1}$. A pressão da bomba não afetou de forma significativa os valores de $\mathrm{CO}_{2 \text { eq }}$ do forwarder, no entanto a rotação do motor influenciou 
de maneira significativa e quadrática, sendo o menor valor, $0,65 \mathrm{~kg} \mathrm{~m}^{-3}$, observados na rotação do motor de 1.475 rpm (Figura 5B).
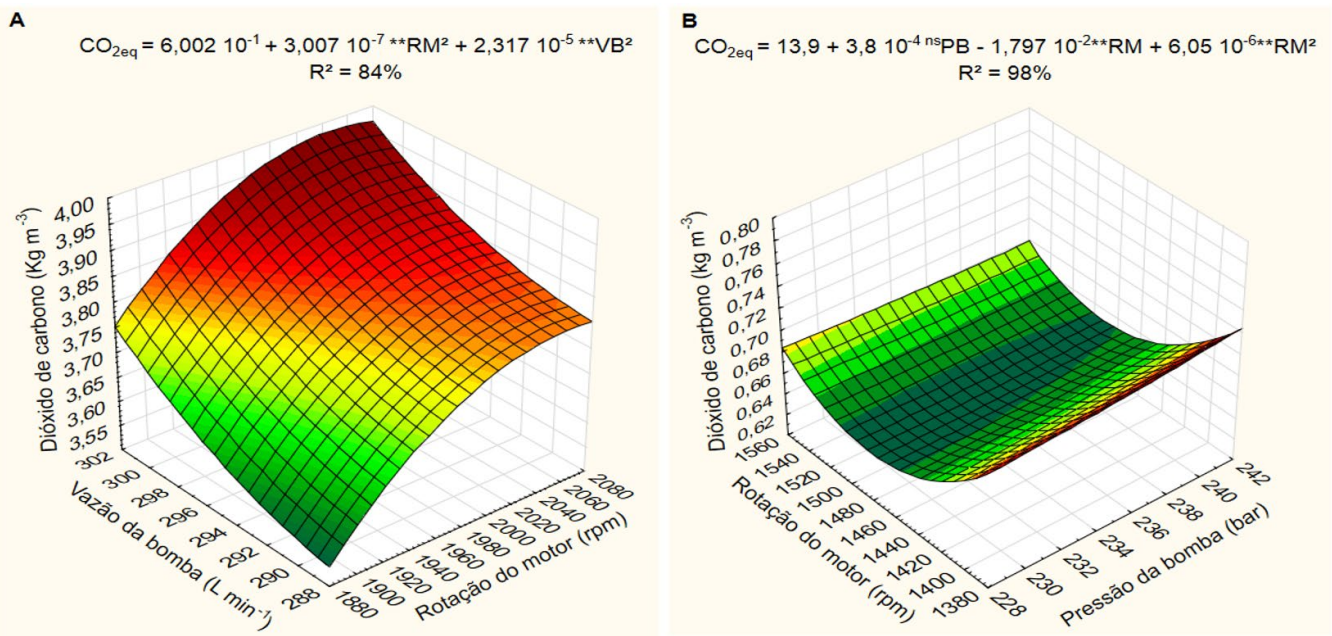

Figura 5. Comportamento e equação ajustada da quantidade de dióxido de carbono $\left(\mathrm{CO}_{2 \text { eq }}\right)$ do harvester (7A) e forwarder (7B). Onde: RM = rotação do motor (rpm); VB = vazão da bomba hidráulica (bar); PB = pressão da bomba hidráulica; ** = significativo ao nível de $1 \%$ de probabilidade; ns = não significativo; e $\mathrm{R}^{2}$ = coeficiente de determinação.

Os menores valores de dióxido de carbono nas menores rotações do motor e vazão ou pressão da bomba hidráulica se deve a redução do consumo horário de combustível e manutenção do rendimento operacional de harvester e forwarder. A redução de $10 \mathrm{rpm}$ na rotação do motor do harvester e forwarder, acarreta a redução de 0,14 ; e $0,08 \mathrm{~L} \mathrm{~h}^{-1}$ no consumo horário de combustível das máquinas, respectivamente. Enquanto a produtividade de harvester reduz em $0,036 \mathrm{~m}^{3} \mathrm{~h}^{-1}$, e a do forwarder aumenta em $0,30 \mathrm{~m}^{3} \mathrm{~h}^{-1}$. Nas combinações de rotação do motor e vazão ou pressão da bomba hidráulica de harvester e forwarder que promoveram o menor impacto ambiental, foi emitido de dióxido de carbono cerca de $4,28 \mathrm{~kg} \mathrm{~m}^{-3}$ de madeira colhida. O valor é $8 \%$ inferior, ao comparado quando o harvester estava operando com rotação do motor em 2.060 rpm e vazão da bomba de $300 \mathrm{~L} \mathrm{~min}^{-1}$ e o forwarder trabalhando com pressão da bomba em 240 bar e rotação do motor em $1.550 \mathrm{rpm}$. Ajustes na rotação do motor promovem impactos expressivos no consumo horário de combustível das máquinas e impactos irrelevantes no rendimento operacional, diminuindo assim a qualidade de dióxido de carbono emitido. Tais resultados corroboram com os encontrados por Spinelli et al. (2018) ao avaliarem picadores de madeira e Man et al. (2016) quando estudaram um motor estacionário, pois de acordo com os autores a redução da rotação do motor provocaram a redução da emissão de dióxido de carbono.

\section{CONCLUSÕES}

Ajustes precisos nas configurações do motor e bomba hidráulica de harvester e forwarder não provocam impactos nocivos no rendimento operacional das máquinas, aumentam a eficiência energética, reduzem o custo de produção e a emissão de dióxido de carbono. Para o harvester os melhores resultados são obtidos nas combinações com rotação do motor em $2.060 \mathrm{rpm}$ e vazão da bomba em $295 \mathrm{~L} \mathrm{~min}^{-1}$ e rotação do motor em $2.000 \mathrm{rpm}$ e vazão da bomba de $300 \mathrm{~L} \mathrm{~min}^{-1}$. Com relação ao forwarder os resultados otimizados são obtidos quando a máquina estava programada para operar com pressão da bomba em 240 bar e rotação do motor em $1.475 \mathrm{rpm}$. 


\section{REFERENCIAS BIBLIOGRÁFICAS}

Ackerman, P., Belbo, H., Eliasson, L., de Jong, A., Lazdins, A., \& Lyons, J. (2014). The cost model for calculation of forest operations costs. International Journal of Forest Engineering, 25(1), 75-81. http://dx.doi.org/10.1080/14942119.2014.903711.

Barnes, R. M. (1968). Motion and time study: design and measurement of work (6th ed., 799 p.). New York: John Willey \& Sons.

Indústria Brasileira de Árvores - IBÁ. (2015). Relatório. Brasília: IBÁ. Recuperado em 17 de fevereiro de 2017, de http://iba.org/images/shared/iba_2015.pdf

Intergovernmental Panel on Climate Change - IPCC. (2006). Guidelines for National Greenhouse Gas Inventories: Mobile Combustion. Recuperado em 4 de setembro de 2018, de https://www.ipccnggip.iges.or.jp/public/2006gl/pdf/2_Volume2/V2_3_Ch3_Mobile_Combustion.pdf

Leite, E. S., Fernandes, H. C., Minette, L. J., Souza, A. P., Leite, H. G., \& Guedes, I. L. (2014). Modelagem do desempenho da extração de madeira pelo "forwarder". Revista Árvore, 38(5), 879-887. http://dx.doi.org/10.1590/S0100-67622014000500012.

Man, X. J., Cheung, C. S., Ning, Z., Wei, L., \& Huang, Z. H. (2016). Influence of engine load and speed on regulated and unregulated emissions of a diesel engine fueled with diesel fuel blended with waste cooking oil biodiesel. Fuel, 180, 41-49. http://dx.doi.org/10.1016/j.fuel.2016.04.007.

Prinz, R., Spinelli, R., Magagnotti, N., Routa, J., \& Asikainen, A. (2018). Modifying the settings of CTL timber harvesting machines to reduce fuel consumption and $\mathrm{CO} 2$ emissions. Journal of Cleaner Production, 197, 208-217. http://dx.doi.org/10.1016/j.jclepro.2018.06.210.

Ramos, C. R., Lanças, K. P., Lyra, G. A., \& Sandi, J. (2016). Fuel consumption of a sugarcane harvester in different operational settings. Revista Brasileira de Engenharia Agrícola e Ambiental, 20(6), 588-592. http://dx.doi.org/10.1590/1807-1929/agriambi.v20n6p588-592.

Santos, D. W. F. N., Fernandes, H. C., Valente, D. S. M., \& Leite, E. S. (2018). Desempenho técnico, econômico e ambiental do harvester em distintas rotações do motor. Scientia Forestalis, 46(118), 319-326. http://dx.doi.org/10.18671/scifor.v46n118.17.

Silva, E. N., Machado, C. C., Fiedler, N. C., Fernandes, H. C., Paula, M. O., Carmo, F. C., Moreira, G. R., \& Coelho, F. E. (2014). Avaliação de custos de dois modelos de harvester no corte de eucalipto. Ciência Florestal, 24(3), 741-748. http://dx.doi.org/10.5902/1980509815733.

Silva, M. L., Miranda, G. M., \& Cordeiro, S. A. Custos. In C. C. Machado (Ed.), Colheita florestal (2. ed.). Viçosa, MG: UFV, 2008. p. 231-260.

Silveira, J. C. M., Fernandes, H. C., Modolo, A. J., Silva, S. L., \& Trogello, E. (2013). Demanda energética de uma semeadora-adubadora em diferentes velocidades de deslocamento e rotações do motor. Ciência Agronômica, 44(1), 44-52. http://dx.doi.org/10.1590/S1806-66902013000100006.

Spinelli, R., Conrado de Arruda Moura, A., \& Manoel da Silva, P. (2018). Decreasing the diesel fuel consumption and $\mathrm{CO}_{2}$ emissions of industrial in-field chipping operations. Journal of Cleaner Production, 172, 2174-2181. http://dx.doi.org/10.1016/j.jclepro.2017.11.196.

Contribuição dos Autores: DWFNS: Curadoria de dados, obtenção de financiamento, investigação, metodologia, escrita - Primeira Redação; DSMV: supervisão, Recursos, Escrita - Revisão e Edição; HCF: Supervisão, recursos, Escrita - Revisão e Edição; APS: recursos, Escrita - Revisão e Edição; CESV: validação, Escrita - Revisão e Edição. 